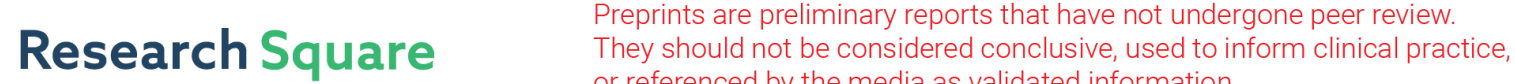 or referenced by the media as validated information. \\ Safe Blast Design for Efficient and Sustainable Underwater Excavation: Art Meets Science!
}

BALAMADESWARAN P ( $\sim$ balamadeswaran@gmail.com )

Anna University Chennai

\section{A.K. Mishra}

IIT (ISM): Indian Institute of Technology

E. Kumar

Anna University Chennai

K. Manikanda Bharath

Anna University Chennai

\section{Research Article}

Keywords: underwater, explosive, initiation, charge factor, safety zone

Posted Date: September 8th, 2021

DOl: https://doi.org/10.21203/rs.3.rs-844947/v1

License: @ (i) This work is licensed under a Creative Commons Attribution 4.0 International License. Read Full License 


\section{Abstract}

Most of the dredging work associated with harbor, port, channel deepening, and other related operation requires underwater blasting due to the characteristics of material being dredged / moved. Underwater blasting is typically used to remove rocks for deepen harbours and channels, creating channels and levees, installing conduits, and other more specialised blasting operations that shall be completed below sea. Usually, such dredging work occurs in deep-water of varying between $16-20 \mathrm{~m}$ in order to remove just few meters of rocks. Hence, this type of blasting activity needs high level of skill and familiarity than equivalent activities carried out above the surface of water because of aqueous layer over the its rock. Therefore, the factors such as selection of drilling parameters and drilling equipment, selection of appropriate explosives and accessories, usage of correct powder factor, determination of safe explosive charges per delay and selection of suitable personnel are studied carefully for accomplishing the successful underwater blasting operations.

In addition to the above, the system shall also address the proper design for the underwater blasts to excavate the rock to the required depth keeping in view the permissible allowances of minimum and maximum depth and fragment size required.

While adopting underwater blasts, adequate safety measures are also defined for safety of men, other vessels in the blasting zone and structures from blasting vibrations. Here, the authors broadly outline their approach with respect to underwater blasting using the existing blasting technology, with a case study.

\subsection{Introduction}

The undersea pre-treatment of hard rocky outcrops on a massive scale helps the dredging operations much easier and it is generally being carried out in the form of drilling and blasting.

Here, the dredging work associated with the underwater blasting activities is mostly related to the harbor and port in order to remove a few meters of mossy rocks (Monteros and Pascual, 2003). Underwater blasting is usually carried out to remove the rock for deepening harbours and channels, making ship lift arrangements, constructing conduits and sewer lines, and establishing pipelines which must be accomplished underwater. This type of blasting activity necessitates more attentive and acquaintance than comparable activities on surface because of the presence of water and loose sediment cover over the rock to be blasted and precision with which drilling can be done.

For productive undersea blasting operational activities, the preceding factors should be taken into consideration:

- Selection of drilling pattern but then equipment for drilling production holes.

- Selection of explosives and accessories with high strength, good water resistance, high density as well as excellent performance under hydrostatic pressure. 
- Calculation of specific charges (charge factors) based on the deepness of the water and the density of the soft sands, rock and explosive quality and strength are required to dislodge the rock, loose sediments and water.

- Safe, reliable and quick (in connecting) initiation system.

- Selection of suitable drilling, charging and hooking-up procedures.

- Dredging of the loose material deposited above the rock prior to blasting.

- Vibration control using the suitable products, delay patterns and charge per delay, etc.

- Need to control over break.

The deep water column and higher output from any dredging operation is a major issue and totally dissimilar from classical dredging operations, and therefore it requires a re-think on the method of pretreatment while designing a blast (Scott, 1996). The following case study outlines a unique approach using cartridged explosives technology which was implemented to protect the surrounding structures and marine environment successfully.

\subsection{Underwater Blasting - Challenges}

In a typical underwater blasting, there are some important facets of the activities as given below that proved to be challenging for carrying out the whole activity in a smooth way.

Geology - The geology consisting primarily of very hard bands wreak havoc on the dredging activity if not adequately broken, and the presence of mudstone may pose problems for silting up drill holes on occasions.

Water Depth - The construction of the wet canals necessitated drilling and blasting activities in regions with water depths greater than $15 \mathrm{~m}$, which are substantially greater than any of those typically seen in conventional underwater pre-treatment projects.

Production Rate - The ocean earthwork excavation equipments may struggle with tougher than anticipated rock structure during the initiation stage of pre-treatment process of rock. Thus, it may mount a considerable pressure to commence the blasting operations at the earliest.

There is a time lag between blasting a region and clearing it of the blasting barge so that it can be excavated, due to the configuration of anchor wires on pontoons and some excavation vessels. Similarly, the drilling barge is to be withdrawn from the drilling location due to unavoidable interruptions and hence the time may be lost because of such withdrawal of the drilling barge to permit movement of ships in the channel.

Operational Dependability - Because of the complexity of the drill and blast process, any single disruption in the drilling, charging, or blasting phases, or pontoon shifting phase, impacted the whole operations. As 
a result, higher availability is essential for all concerned units involved to facilitate the drill and blast process continually.

Climatic - During the summer months, air temperature is often more than $40^{\circ} \mathrm{C}$ and attain as high as $50^{\circ} \mathrm{C}$. At these temps, the machinery and men together start to fail, particularly on an all metal-made platform. Besides the above, the effects of tidal waves on pontoons exacerbate the growing issue of flexing casings.

Security - One of the big issues for this activity is explosives safety. The Port authorities are typically quite stringent on explosives management, requiring that all explosives transit, storage, and usage be directly supervised by qualified individuals. The additional security related to explosives dispensed with increased charges and undue interruptions to the drill and blast process.

Delayed Feedback on Blast Results - The drilling and blasting crew are completely unaware of what is going on beneath the surface of the sea. If uncommon situations arose, one had to keep all the indications together and mentally visualise what was going on down in the depths. Unlike a typical surface blast, where the results can be inspected and judged almost immediately, delayed excavation in the sea bed after the blast makes it difficult to assess the effectiveness of any changes to the drill and blast operation immediately.

\subsection{Underwater Blast Design - Case Study 3.1 Location of the Site}

The port is located at latitude $18^{\circ} 56.43^{\prime} \mathrm{N}$ and longitude $72^{\circ} 56.24^{\prime} \mathrm{E}$ in the State of Maharashtra, India. It shares a common navigational channel (main harbour channel) with the main port. The port is also sheltered by continent of Kankan on the east and landmass of Mumbai in the west. During the year, the harbour's deep waters provide sufficient protection for ships.

The underwater drilling and blasting activities for the capital dredging works in the Port (as shown in Fig. 1.0), where the field studies have been conducted possess the objectives of planning of optimum drilling, blasting pattern and initiation system for the underwater blasts to excavate the rock to the required depth and also to estimate safe explosive charges per delay to protect various structures like Naval Dock Yard, existing Births of Port Trust, etc. located at various distances from the blasting sites against blast vibrations. In addition, proper measures are to be adopted also proposed for safety of men, other vessels and structures in the blasting zone against blast vibrations.

\subsection{Rock Properties}

The rock formation basically consists of Basalt and Laterite with silt covers of varying thickness (ranging between 1.5-9.0 m). The silt has been removed initially with conventional dredging operations before the drilling operation was commenced. About 18 rock blocks of not less than $30 \times 30 \times 30 \mathrm{~cm}$ specimens are obtained for determining the physico-mechanical properties from the berth pocket area of Port. The cores 
were obtained, by diamond drilling, from all these rock blocks were tested in the laboratory for determination of the Uni-axial compressive strength and the density of the rock samples (Sanchidrián et al, 2014; Hamdi and Karrech, 2015). The samples had more than $40 \mathrm{MPa}$ of uni-axial compressive strength, i.e., 56 percent of the samples had more than $40 \mathrm{MPa}$ strength. This indicates that the compressive strength of the basalt at the sea bed is not uniform and varies quite widely (Domenico, 1982). Similarly, the survey data including the coordinates of the blasting areas have been provided to facilitate the planner to determine (or) quantify the depth of water, thickness of various materials viz. clay, weathered rock, hard rock and fresh rock to be blasted at different locations within each area.

\subsection{Blast hole diameter}

Generally, the selection of blast hole diameter is governed by several factors (Liao et al, 2020). The dredger as shown in Fig. 2.0, was used at the project is designed to have the capacity of mucking or lifting a maximum size of $0.7 \times 0.7 \times 0.7 \mathrm{~m}$ (no dimension more than $0.7 \mathrm{~m}$ ) of rock from the seabed with a production capacity of $3,500 \mathrm{~m}^{3}$ per day. Taking into consideration the rock type, depth of blasting, the conditions prevailing in the Port and dredgers deployed, the drill hole diameter used for the underwater blasting in fragmenting the basalt rock available at sea bed was $150 \mathrm{~mm}$.

\subsection{Burden and Spacing}

It is one of the utmost key factors in the design of blasts (Hagan, 1983; Hustrulid, 1999). The burden of $2.25 \mathrm{~m}$ was considered in the initial blasts until the blast pattern was optimised and the spacing, which controls the mutual effect between holes in the same row calculated based on established norms, is 2.75 $\mathrm{m}$ for the initial blasts.

The normal way to compensate for the deviation of blastholes is to minimise the burden and spacing until the cost of dredging operation is optimized (Rustan, 2018).

\subsection{Sub grade drilling}

In order to avoid leaving a ridge, bootleg or toe formation in the sea floor after blasting, the blast holes are required to be penetrated below the ultimate floor level. A sub-grade drilling of $2.0 \mathrm{~m}$ was suggested for the trial blasts based on preliminary calculations.

\subsection{Stemming}

A suitable length and consistent stemming column will improve rock fragmentation and dislodgment by gas energy while minimizing early discharge of high-pressure explosive gases from the drillhole (Zhou et al, 2019). Stemming also reduces the transmission of energy through water in the form of waves and hence it was suggested to maintain a minimum stemming length of $1.5 \mathrm{~m}$.

\subsection{Blast hole and Charge length}

With blasting, obtaining very precious depth like machine cutting is not possible. Therefore, the blasting has to be carried out to a depth which is slightly more than what is originally required (Cooper, 1958). 
This results in carrying out the blasting upto the maximum permissible allowance of $0.5 \mathrm{~m}$ below the minimum required level of the sea floor (i.e., upto $16.5 \mathrm{~m}$ below the water level). This is essential to ensure that the sea floor level, after blasting, is always below the required level. This ensures that blasting for the second time is not required to obtain the minimum depth of water as it is difficult, cumbersome, time consuming and costly. After blasting, dredger was allowed to carry out the operation up to the required depth $(16.0 \mathrm{~m})$ leaving some blasted material at the sea floor, if necessary. The blast hole length, to obtain an average charge length of $5.0 \mathrm{~m}$, should be $7.0 \mathrm{~m}$ covering a sub-drilling of $2.0 \mathrm{~m}$.

\subsection{Selection of Explosives}

While considering the explosives for underwater blasting, it shall be moisture-resistant and possess long shelf life (Gustafsson, 1973). The storage safety period varies according to the actual type and also the climatic conditions in which it is stored.

- Cap sensitive Nitrate mixture based watergel explosives in Couplable Plastic Tubes (CPT) (class 2 as per Explosives Act) of $125 \mathrm{~mm}$ (OD) was used at Port. Each cartridge contains $6.25 \mathrm{~kg}$ of explosive as shown in Fig. 3.0. These packaged explosives would be suitable for charging required quantity of explosives in the blastholes quickly, safely and efficiently for the undersea explosion (Tripathi and Shirke, 2015).

- It should have higher bulk strength in order to make the most of each blast hole.

- The explosive shall possess high water resistant in the short span.

- It should have proper density of the packaged explosive to conquer any muddy or slushy issues at the bottommost part of the drillholes.

- The explosive shall be capable of retaining their sensitivity when subjected to high hydrostatic pressure.

- Under any conditions the general performance of an explosive improves with an increase in the cartridge diameter particularly extending the utilization of explosive energy for fragmentation (Mohamad et al, 2018) and hence a cartridge diameter of $125 \mathrm{~mm}$ was proposed. It also ensures better coupling of the explosives in the drill hole of $150 \mathrm{~mm}$ diameter.

- A very interesting feature of the packaged explosive to be used here is that the plastic canister of the explosive may be fitted with an external thread and the cartridges can be screwed into internallythreaded outer sleeves of other cartridges, known as 'Seislok couplings'. This enables a train of cartridges to be coupled together to form a single unit for charging into the bore hole.

\subsection{Specific Charge}

The basic difference between surface and underwater blasts are that the former has two to three free faces, where as in the latter case the water and the loose overburden that rests upon the rock create a 
confining force or pressure on the top surface and on the additional free face making the expansion, fragmenting and movement of the blasted rock towards these free faces more difficult (Fletcher et al, 2004; Singh et al, 2016). Hence the specific charge for underwater blasting is to be higher than surface blasting of similar rock. Keeping in view all the concerned parameters and adopting established empirical formulae, a specific charge of $2 \mathrm{~kg} / \mathrm{m}^{3}$ is suggested for ensuring effective fragmentation for the initial blasts until it was optimised to the range of 0.87 to $1.16 \mathrm{~kg} / \mathrm{m}^{3}$. Thus, it has provided the total explosive charge per hole of ranging from $62.5 \mathrm{~kg}$ with a charge length of $5.0 \mathrm{~m}$ which is reasonable for under water-blasting of this nature.

\subsection{Choice of Initiation System}

The following factors influenced the selection of suitable initiation system for the operation.

- The barge is power-driven by winches with electric motor, and will have numerous communication components. It is therefore noted that the usage of detonators of electric type that would be too dangerous in such an environment and hence it should be avoided. A shock-tube product is therefore chosen as it is proven to be safe even during the lightning (Sastry and Ram Chandar, 2004).

- The detonators must be able to withstand extreme head pressures.

- The lines lowered into the hole must be sturdy to endure possibly harsh handling while charging and recovering (through the casing pipes) process.

- NONEL was taken into account owing to its capacity to give the elastic characteristic slightly under stress without adversely impacting the tube's effectiveness (Hemant and Mishra, 2018).

- In order to promote speed, safety, reliability in the operation and to ensure efficient hole charging cycle times, the blast connection system had to be simple, dependable, water resistant, and quick.

\subsubsection{Initiation Sequence}

By using timing delays, sizable explosive charge weights can be divided into a series of lesser charge weight (Langefors and Kihlstrom, 1978). Delay detonators are inserted to attain time-delay between consecutive blastholes detonations. It has been emphasized that the accurate release of explosive energy in a series of blast holes yields better fragmentation and reduces ground vibrations. Hence, an accurate control is necessary over the detonation sequence to bring direct impact on over all blast performance.

The initiation system proposed for the above Port basically consists of Non-Electric shock tube initiation (NONEL) provided with delay detonators and trunklines. It was recommended that the holes are charged with two numbers of down the hole shock tube delay detonators to improve reliability of the initiating sequence system and to avoid misfires, which are different to be detected and handled in underwater blasting. In double initiation system, even if one detonator fails, the other will work. Here, delay interval of 
$17 \mathrm{~ms}$ (No.6 strength) between the drillholes in the same row and $25 \mathrm{~ms}$ (No.6 strength) between the rows of holes are suggested with down the hole delay of 170-200 ms (No.8 strength). Moreover, welding was also carried out on the barge for fixing and adjustment of the length of the casing pipe, hence NONELs are safer. Similarly, the scaled distance predictor equations obtained are often susceptible to the scattered delay timings of pyrotechnic detonators such as NONELS. The scatter in delay timing causes hole overlapping and thus increases the maximum charge weight per delay (Agrawal and Mishra, 2021). Hence the possibility of using electronic detonators can not be ruled out in such cases.

\subsection{Drill And Blast Barge}

There is no standard design for constructing Drill and Blast Barge, because many of these structures are built for specific works and are taken apart afterwards. The choice of one or another depends upon the environmental conditions, tides, waves, etc., and also on the magnitude of the operation. Here, the drilling and blasting operations will be carried out from a pontoon with an approximate dimension of 70.25 meter.

Drilling from the side of the raft as shown in the Fig. 4.0, will fulfil the objective of carrying out maximum number of blastholes simultaneously. The rafts are anchored to various fixed points to avoid lateral movements and allow movement, when necessary to change position to the new row of holes. The vertical effect of the waves can be overcome with special devices in the drilling rigs which maintain a constant pressure against the bottom of the blasthole.

The winches and anchor wires are moved by compressed air, hydraulic, diesel or electric energy. Also, the rigs are usually set up with high towers or masts which lessen drill steel lengthening and tubing operations. As a work surface, a $2.0 \mathrm{~m}$ wide sideboard is connected to the barge's large side. Eight numbers of truck mounted hydraulic drilling machines were mounted on the barge for drilling simultaneously 8 holes.

Key components of the drill and blast barge include the following.

- Drill machines

- Compressors

- Diesel Generator sets

- Anchors and Winches

- Water Pump

- Office \& Workshop Containers

- Workshop

- Barge Positioning System

- Survey office 
The self-propelled barge was taken to an estimated position and further banked on four anchors and winches to place itself and move it exactly from one row of holes to the other, which are parallel. Anchors were relocated with the help of yanks whenever required. The precise positioning of the barge to drill each row of the holes is achieved by a Global Positioning System of $2.54 \mathrm{~cm}$ (one inch) accuracy.

\subsection{Drill And Blast Operation}

The Drilling and blasting area would be divided in two areas. Area-l of $700 \mathrm{~m}$ length of the birth pocket towards the North and the remaining $350 \mathrm{~m}$ length (Area - II) towards the South. Area - I will be drilled and blasted to produce the material for the dredging operation. After completing the Area - I, Area - II will be drilled and blasted. This facilitates uninterrupted operation of drilling, blasting and dredging before the blasted rock gets consolidated thereby making the dredging operation easy and efficient. Drilling, blasting and dredging will be carried out at two blocks alternatively as indicated in Fig. 5.0. The drill and blast operation is cyclic in nature consisting of the following events.

\subsection{Drilling}

The drilling operation will commence with dropping the casing pipe to the sea floor as shown in Fig. 6 . Threaded mild steel pipe with a wall breadth of $8.5 \mathrm{~mm}$ and an inner diameter of $175 \mathrm{~mm}$ should be used for making the casing pipe. Once the casing pipe is brought into a position, the retrieval ring of $200 \mathrm{~mm}$ ID is placed around the casing, the $150 \mathrm{~mm}$ drill bit and drill string is lowered through the casing pipe to start drilling. The collapse of drill hole walls are prevented by the casing pipe as it normally permit them to be occupied with the drill cuttings or any other debris when removing the drill strings, typical in underwater drillings.

The hole depths are calculated by the drilling engineer and a marking made on the drill steel. When the correct hole depth is reached, the drill cuttings are completely rinsed and the drill string is taken away, and the hole will be presented for charging as shown in Fig. 6.0.

\subsection{Hole Charging}

The CPT explosive cartridges would be primed with $25 \mathrm{~m}$ length downline NONEL. The holes are charged with a predetermined quantity (as per depth of the hole and strength of the rock) of specially made high density and cap-sensitive nitrate mixture based watergel explosives in CPT. One end of the down line is connected to the explosive charge (primed) and the other is connected to a floating device to facilitate reaching water surface for easy identification and recovery. It is essential to select shock tubes of sufficient length keeping in view the depth of water, the depth of the rock to be blasted, maximum tide prevailing in the area, current of water, etc. to facilitate easy connection between the drillholes.

Primed cartridges are to be prepared just before the drillholes are required to be charged with explosives as shown in Fig. 7.0. The primed cartridges so prepared are stored safely till it is delivered for charging of 
drillhole.

\subsection{Downline Recovery}

Once the hole is charged and stemmed with stemming material, the casing was raised approximately 2.0 $\mathrm{m}$ and the recovery ring was permitted to drop down to the bottom of the sea. The ring was snapped to the adjacent part and then lifted upwards towards the barge through an attaching rope in a quick pulling movement as shown in Fig. 8.0. This act gathers both downline shock tubes and draws them out of the case, then clear of the casing's lower part, and eventually return to the barge.

\subsection{Tying-up}

The downlines are connected from one side of the row, progressing to the other side as per the hook up plan. Two guide ropes linked to anchored marker buoys demarcate aside of the blast and start serving as safeguarding points for each end of the row of linked down the lines (as shown in Fig. 9.0). When using shock tube double delay detonators, it was critical to keep them properly assembled and simply identifiable by different coloured tapes. It was accomplished through the use of Detonator Buoyancy Devices (DBDs) which ensured the detonator floating over the surface of the water with a minimum buoyancy of $5 \mathrm{~kg}$. The DBDs are serially numbered, colour coded, and taped about $30 \mathrm{~cm}$ from each bunch block so that the position of detonators was instantly known, even after a blast.

The colour coding signifies whether the bunch block is a lead-in initiation detonator, a standard blasthole detonator. The colour coded floating devices were used in such a manner, to ensure that they float on the surface of water for easier identification. Similarly, the blasting area will be demarcated by a floating fence to prevent any inadvertent entry of unauthorised persons. Table 1.0 spells out the summary of controlled blast design which was implemented in the aforesaid Port for the dredging operations. However, fragmentation control through efficient blast design and its influence on productivity is a demanding job for the practicing blasting engineer in the underwater blasting situations as actual explosive energy utilised in the blasthole is unknown (Scott and Onederra, 2015; Roy et al, 2016). 
Controlled Blast Design for Dredging Operation

\section{SI. Parameter}

No.

1. Blast hole diameter

2. Burden

3. Spacing

4. Length of sub-grade drilling

5. Inclination of the holes

6. Stemming length

7. Drilling pattern to be followed

8. Specific charge

10. Loading Density

11. Initiation System/Detonators recommended

12. Type of explosive recommended

Primer/Booster

Production blasting

\begin{tabular}{ll} 
Sinking cut & 1.2 to $1.5 \mathrm{~kg} / \mathrm{m}^{3}$ \\
$\begin{array}{l}\text { Production } \\
\text { blasting }\end{array}$ & $1.0 \mathrm{~kg} / \mathrm{m}^{3}$ \\
\hline
\end{tabular}

$12.5 \mathrm{~kg} / \mathrm{m}$ to $15.5 \mathrm{~kg} / \mathrm{m}$

NONEL with down the hole and surface delays

Cap sensitive nitrate mixture based Watergel explosives in CPTof $125 \mathrm{~mm}$ (OD)

Column Charge Cap sensitive nitrate mixture based watergel explosives in CPT of $125 \mathrm{~mm}$ (OD)

14. Delay interval

Between holes

17 milliseconds

in the same

row

Between rows

Per shift

25 / 42 milliseconds

16. Number of rows of holes planned to be drilled and blasted

Per Day

18. Initiation system recommended

19. Method of connecting NONELs
6 to 8

12 to 16

Inverse initiation

Series

The pattern of drilling followed are the precise rectangular drilling and staggered rectangular drilling patterns to facilitate the initiation sequence of row-by-row as shown in Fig. 10.0 in order to main the pace of subsequent dredging operation by both trailer suction hopper dredger and cutter suction dredger. 
Inadequate rock fragmentation will cause a slew of issues, including increased production costs because secondary breaking is impractical in an undersea ecosystem (Dehghani et al, 2020).

\subsection{Repositioning the Barge}

After the row had been effectively tied up and examined by the blaster, the guide ropes were deployed, and the barge was pulled back to a point of the subsequent row using GPS. After drilling, charging and hooking up all the rows for the day, the barge was retracted its position to a distance of 200 meters which is considered to be safe from the site of blasting. No swimmers or divers were allowed to stay within the vicinity of $1,000 \mathrm{~m}$ from the blast site during the blasting operations.

\subsection{Post-Blast}

The blaster examines the last bunch block of each row immediately after firing a blast to confirm that all downlines have correctly fired. The all-clear signal was then given, and the dredger has been immediately moved to the required position for dredging. To avoid hazard to livestock near the blasting premises and also to prevent the reuse of DBDs, all shock tubes and DBDs were retrieved from the water by a small powered boat. The service of a diver was used to inspect the sea floor during the initial sinking cut and trial blasts for first hand information about the results of the blast. The different stages of underwater blast are shown in Fig. 11.0.

\subsection{Blast Induced Ground Vibrations In Underwater Blasting}

Followed by the detonation, energy is distributed rapidly into the surroundings in underwater blasting. This energy has the following consequences:

- Stress waves transmitting through the neighbouring ground strata

- Stress waves transmitting centrifugally through the sea water

- Stress waves echoed from the surface of sea water and seabed

- Causing the gas bubbles to pulsate

- Physical movement of the water surface and release of air blast energy.

As the water and water-saturated structures are possessing efficient shock wave transmission characteristics than dry conditions, the transition of explosive energy into seismic energy is usually greater in water or moisture formations than in dry situations (Siskind, 2000; Venkatesh, 2005).

In locations where extreme vibrations could harm nearby equipment or structures, extra care such as by deploying short-delay interval initiating system and limiting the quantity of explosives per delay (Paurush 
et al, 2021). The peak particle velocities (PPV) of blast-induced ground vibrations was restricted to less than 5 and $10 \mathrm{~mm} /$ second at Naval Dock Yard and at the existing berths of Port Trust respectively, as recommended by the Directorate General of Mines Safety (Table 2.0). Hence, the design for the blast was such that no vibration limits were exceeded and was based on the constants of the rock at the seabed.

Table 2.0

Directorate General of Mines Safety (DGMS) suggested peak particle velocities (PPV) various types of civil structures can tolerate without damage \{DGMS (Tech) (S\&T) Circular No.7 of 1997\} (Anon, 1997)

Type of structure

Max. Permissible PPV, $\mathrm{mm} / \mathrm{s}$

\section{Dominant excitation frequency, $\mathrm{Hz}$}

$<8 \quad 8-25 \quad>25$

(A) Buildings / structures not belonging to the owner

\begin{tabular}{lllll} 
(i) & $\begin{array}{l}\text { Domestic houses/structures (kutchha brick \& } \\
\text { cement) }\end{array}$ & 5 & 10 & 15 \\
\hline (ii) & Industrial buildings (RCC \& framed structures) & 10 & 20 & 25 \\
\hline (iii) $\begin{array}{l}\text { Objects of historical importance \& sensitive } \\
\text { structures }\end{array}$ & 2 & 5 & 10
\end{tabular}

(B) Buildings belonging to the owner with limited span of life

\begin{tabular}{lllll} 
(i) & $\begin{array}{l}\text { Domestic houses/structures(kutchha brick \& } \\
\text { cement) }\end{array}$ & 10 & 15 & 25 \\
\hline (ii) & Industrial buildings (RCC \& framed structures) & 15 & 25 & 50
\end{tabular}

The presence of water (over the rock to be blasted) contains the blasting energy and there was no fly rock from the blasts (Raadt, 1976; Ramulu et al, 2004). Only the marine life in the immediate vicinity of the blast, if any was also less affected by the blasting. Several studies have earlier demonstrated that marine blasting activities have no long-term effects on the marine environment. Explosives detonated in or near fish habitat may pose a threat, injury, and/or death of fish, as well as harmful variation, destruction, or devastation of their ecosystems, even at a significant distance from the point of explosion. (Wright and Hopky, 1998; Martin, 2015). Blasting can result in death, physical harm, auditory tissue damage, irreversible and momentary threshold shifts, changes in behavior, and reduced egg and larvae feasibility in few cases (Faulkner et al, 2006). However, the required safety measures are taken into account with following the guidelines with reference to the safety distances for different explosives as shown in Fig. 12.0. Accordingly, the barge could pull back to a safe distance of around $200 \mathrm{~m}$ after drilling, charging and hooking up all the rows are completed for the day. No swimmers or divers are allowed to stay within the vicinity of $1,000 \mathrm{~m}$ from the blast site during the blasting operations. To safeguard historic 
buildings and the sea environment from blast vibrations, rather more cautious vibration thresholds are mandated.

\subsection{Conclusion}

In the underwater blasting operations, the deployment of dredging equipment necessitates a significant capital outlay. The outcome of underwater blasting activities has a significant influence on the performance of these machines. Hence, an effectively designed controlled blasting methodology help in timely achievement of dredging targets. The present study convinced that a controlled blasting of rock in the undersea conditions require a unified cycle of operations including blast design pattern, blast implementation plan and blast optimum analysis (Balamadeswaran and Mishra, 2020). It's not easy to define an industry's future vision. The world is changing quicker than it has ever been before. Every day, new technologies are invented that have an impact on how people live (Sánchez and Hartlieb, 2020). In the research work, an energy-controlled blast design has been suggested for the underwater blasting considering the various typical uncertainties with respect to the marine floor irregularities, rockmass properties, marine environment and surrounding coaster structures.

The results of the investigations that have been done in the different areas, led to design the blasts to be carried out for the proper breakage of rocky formation existing in the undersea situations, and the following conclusions can be drawn.

- Assuming a safe level of ground vibration as 5 and $10 \mathrm{~mm} / \mathrm{sec}$ for safety of coastal structures, the maximum permissible charge per delay was calculated using site specific empirical equation. However, the initiation sequence maintained in the multi-rows of a blast with the delay between the successive shots is not less than 8 ms proved to keep the blast-induced vibrations less than $2 \mathrm{~mm} / \mathrm{s}$ in the coastal structures placed at a distance of about $500 \mathrm{~m}$ from the site of blasting.

- Blasting of 48 holes to 64 holes in a round had created the required material with proper fragmentation for the dredging apart from controlling the blast-induced vibrations.

- The fragmentation of blasts in the 2 nd and subsequent rows are found to be heavily influenced by the number of blasted holes in the 1 st row as it was reported during the dredging operations.

- The packaged explosive maintained with proper density in CPT is found to tolerate the sludge and mud problems as the explosive cartridges penetrate into the mud and then displace it in the hole in the event of partial collapse of the drill hole walls.

- The initiation sequence of row-by-row adopted in the rectangular and staggered drill patterns have produced adequate fragmentation for the subsequent dredging operations.

- Naturally formed boulders of varying sizes might roll down from the neighbouring areas and get accumulated at local depressions. If the explosive charge is terminated in the bed rock, the boulder will not get blasted. Hence, while the drilling is carried out through the loose boulder present at the sea bed and then the explosive charge length in the hole is extended for effective breakage. 
However, surveillance of underwater blasts with appropriate instrumentation will be extremely beneficial in not only optimising the drilling and blast design but also preventing ecological consequences under sea.

\section{Declarations}

\section{Acknowledgements}

Thanks are due to the Anna University Chennai and Indian Institute of Technology (ISM) Dhanbad for granting necessary permission to publish the paper. Thanks are due to Shri. R. Ramesh, RKS Drilling Services Chennai for rendering necessary assistance during the study.

\section{Conflict of Interest}

The authors declare that they have no conflict of interest.

\section{References}

1. Agrawal H, Mishra AK (2021) An Analytical Approach to Measure the Probable Overlapping of Holes Due to Scattering in Initiation System and Its Effect on Blast-Induced Ground Vibration in Surface Mines. Mining Metallurgy Exploration 38:485-495

2. Anon, (1997), Technical Circulars of No7 of 1997 issued by Directorate General of Mines Safety, Govt. of India

3. Balamadeswaran P, Mishra AK (2020) Controlled blasting practices in quarries for sustainability: a case study. J Mines Metals Fuels 68(8):251-263

4. Choudhary BS (2018) Drilling and Blasting Techniques for Sinking a Well in a Water Reservoir-A Case Study. Mining Engineers' Journal 20(3):21-26

5. Cooper HR (1958) Practical Dredging and allied subjects, Brown. Son \& Ferguson Ltd., Glasgow, p 431

6. Dehghani H, Babanouri N, Alimohammadnia F, and Mokhtar Kalhori (2020), Blast-Induced Rock Fragmentation in Wet Holes, Mining, Metallurgy \& Exploration, 37, pp.743-752

7. Domenico SN, (1982), Acoustic wave propagation in air-bubble curtains in water Part l: History and theory, Geophysics, Vol. 47, pp. 345-353

8. Faulkner SG, Tonn WM, Welz M, Schmitt DR (2006) Effects of explosives on incubating lake trout eggs in the Canadian Arctic. North Am J Fish Manag 26:833-842

9. Fletcher K, Briggs M, Grant R, Cano ML, (2004), Deep Water Blasting on the River Nile in Southern Egypt, Proceedings of the International Conference on Explosives and Blasting Techniques, Volume.1, pp.1-14

10. Gustafsson R (1973) Swedish Blasting Technique. SPI, Gothenburg, Sweden, p 323 
11. Hagan TN, (1983), The influence of controllable blast parameters on fragmentation and mining costs, Proceedings of the First International Symposium on Rock Fragmentation by Blasting, pp. 3151, Luleå, Sweden

12. Agrawal H, Mishra AK (2018) Evaluation of initiating system by measurement of seismic energy dissipation in surface blasting. Arab J Geosci 11(13):345

13. Hamdi E, Karrech A, (2015), A Methodology for Rock Mass Characterisation to Control Blast-induced Vibrations, Proceedings of 11th International Symposium on Rock Fragmentation by Blasting, 24-26 August 2015, Sydney, Australia, pp.89-96

14. Hustrulid W (1999) Blasting Principles for Open Pit Mining, Volume 1-General Design Concepts. A.A.Balkema, Rotterdam, 1013p

15. Jimeno CL, Jimeno EL, Carcedo FJA, Ramiro YV (1995) Drilling and Blasting of Rocks. A.A.Balkema, Rotterdam, p 391

16. Martin D, (2015), Scientific Evaluation of Fauna Sensitivity to Blasting, Proceedings of 11th International Symposium on Rock Fragmentation by Blasting, 24-26 August 2015, Sydney, Australia, pp.519-526

17. Mohamad ET, Yi CS, Murlidhar BR, Saad R (2018) Effect of Geological Structure on Flyrock Prediction in Construction Blasting. Geotech Geol Eng 36:2217-2235

18. Monteros EH, Pascual JA, (2003), Underwater blasting in Algeciras-Spain for the world biggest floating dock, Proceedings of EFEE Second World Conference on Explosives and Blasting Techniques, $10 \sim 12$ September 2003, Prague, pp.101-107

19. Langefors U, Kihlstrom B (1978) The modern technique of rock blasting. John Wiley and Sons, New York, p 405

20. Liao X, Khandelwal M, Yang H, Koopialipoor M, Murlidhar BM (2020) Effects of a proper feature selection on prediction and optimization of drilling rate using intelligent techniques. Engineering with Computers 36:499-510

21. Paurush P, Rai P, Sharma SK (2021) Selection of Blasting Design Parameters Affecting Peak Particle Velocity-a Case Study, 38. Mining, Metallurgy \& Exploration, pp 1435-1447

22. Raadt B (1976) Shockwave - Critical charge distances to objects in water. S.E.E

23. Ramulu M, Chakraborty AK, Raina AK, (2004), Influence of Burden on Intensity of Ground Vibrations and Air Overpressure in Opencast Bench Blasting, Proceedings of the Annual Conference on Explosives and Blasting Technique, Vol. 2, pp. 465-478

24. Roy MP, Paswan RK, Sarim MD, Kumar S, Jha R, Singh PK (2016) Rock fragmentation by blasting-A review. J Mines Metals Fuels 64(9):424-431

25. Rustan PA, (2018), The influence of blasthole standard deviation (BSD) on fragmentation, Proceedings of 12th International Symposium on Rock Fragmentation by Blasting, 11-13 June 2018, Luleå, Sweden, pp.651-664 
26. Sánchez F, Hartlieb P (2020) Innovation in the Mining Industry: Technological Trends and a Case Study of the Challenges of Disruptive Innovation, 37. Mining, Metallurgy \& Exploration, pp 13851399

27. Sanchidrián JA, Ouchterlony F, Segarra P, Moser P (2014) Size distribution functions for rock fragments. International Journal of Rock Mechanics Mining Science 71:381-394

28. Sastry VR, Chandar R, K (2004) Shock Tube Initiation for Better Fragmentation: A Case Study, Fragblast. International Journal for Blasting Fragmentation 8(4):207-220

29. Singh PK, Roy MP, Paswan RK, Sarim M, Kumar S, Ranjan Jha R (2016) Rock fragmentation control in opencast blasting. J Rock Mech Geotech Eng 8:pp.225-237

30. Siskind DE (2000), Vibrations from Blasting. Int. Soc. of Explosives Engineers, Cleveland, Ohio, 120p

31. Scott A (1996), Blastability and blast design, In: Mohanty B (ed), Fragblast 5, Proc 5th International Symposium on Rock Fragmentation by Blasting: Rotterdam: Balkema, pp.27-36

32. Scott A, Onederra I, (2015), Characterising rock mass properties for fragmentation modelling, Proceedings of the 11th International Symposium on Rock Fragmentation by Blasting, Sydney, NSW, August 24-26, pp.149-160

33. Tripathi GR, Shirke RR (2015), Underwater Drilling and Blasting For Hard Rock Dredging In Indian Ports - A Case Study, International Conference on Water Resources, Coastal and Ocean Engineering (ICWRCOE 2015), Aquatic Procedia, 4, pp.248-255

34. Venkatesh HS (2005) Influence of total charge in a blast on the intensity of ground vibrations - Field experiment and computer simulation, Fragblast. International Journal for Blasting Fragmentation 9(3):127-138

35. Wright DG, Hopky GE (1998), Guidelines for the Use of Explosives in or near Canadian Fisheries Waters, Canadian Technical Report of Fisheries and Aquatic Sciences 2107, 34pp

36. Zhou J, Koopialipoor M, Bhatawdekar R, Fatemi SA, Tahir MM, Armaghani DJ, Li C (2019) Use of intelligent methods to design effective pattern parameters of mine blasting to minimize flyrock distance. Nat Resour Res ,29(11):1-15

\section{Figures}




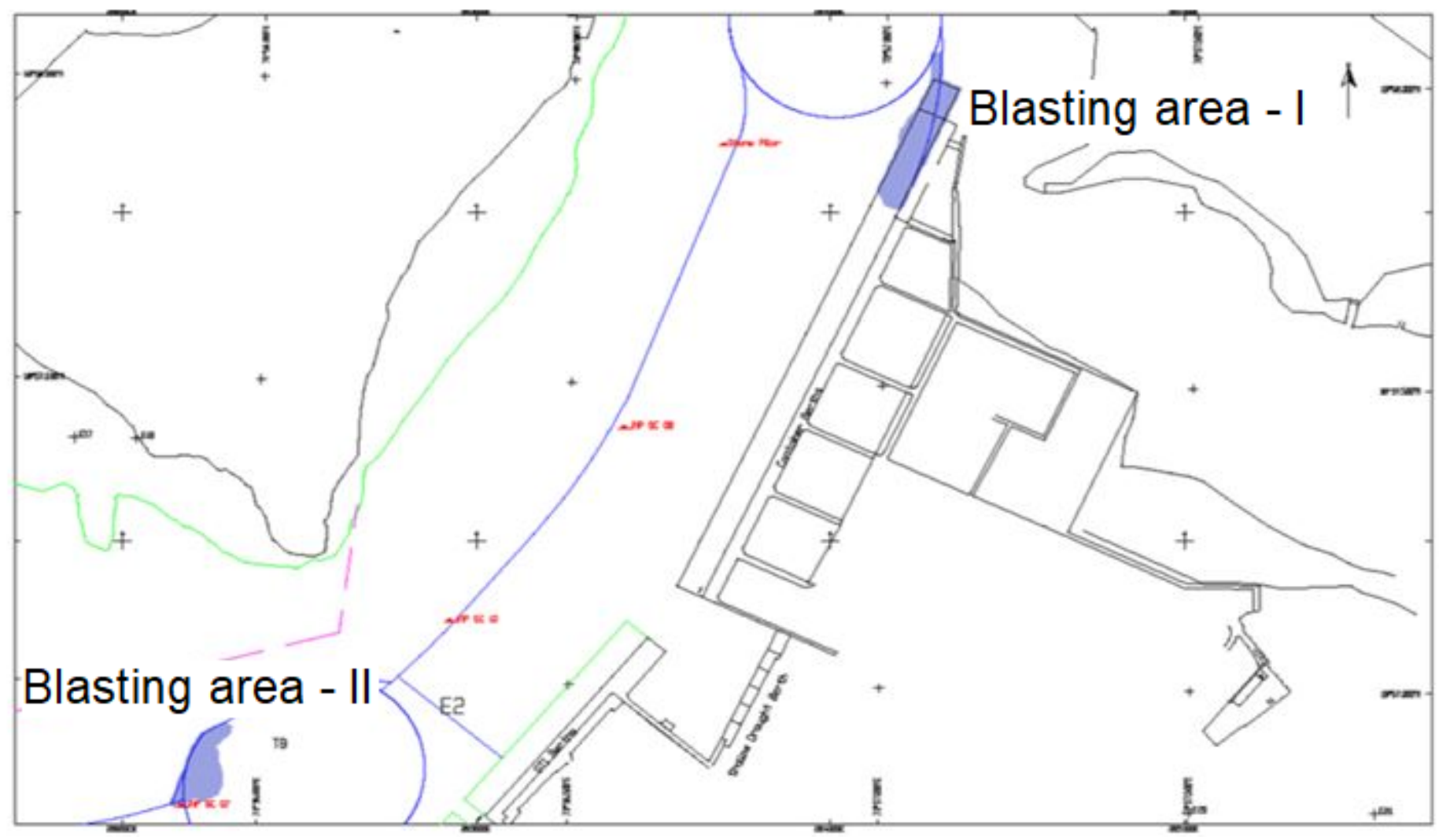

Figure 1

Areas designated for Capital Dredging in the Port

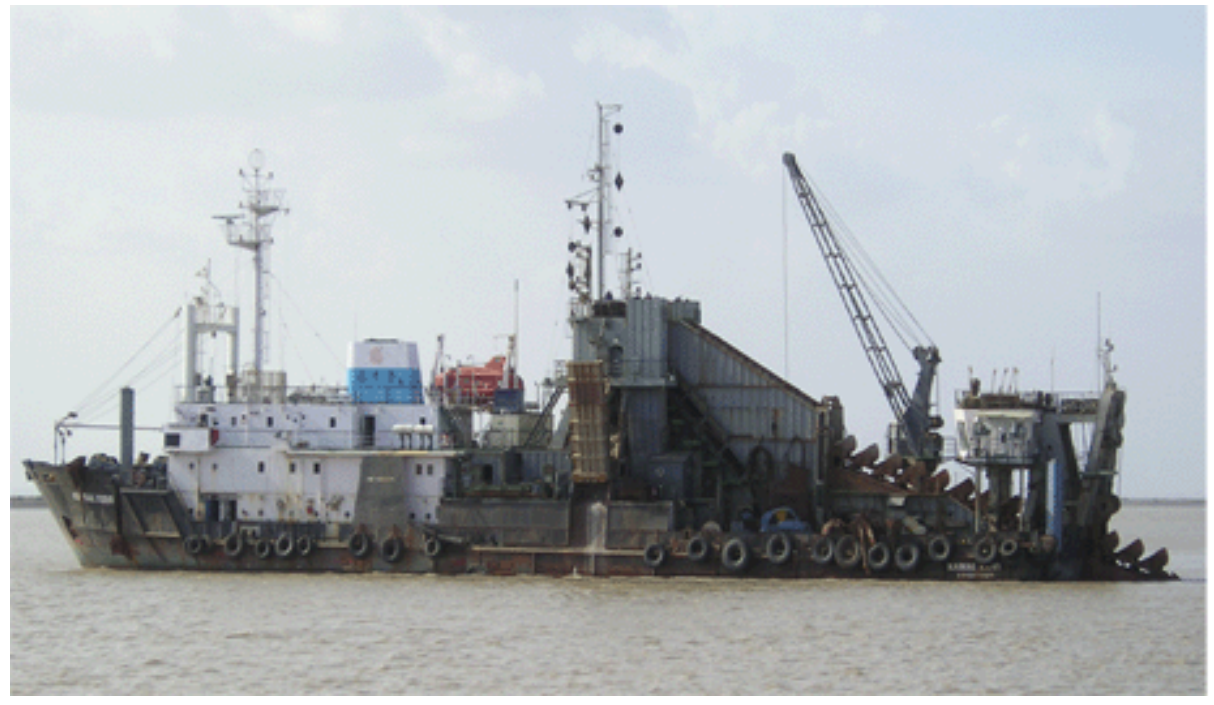

Figure 2

Dredger used for Excavation 


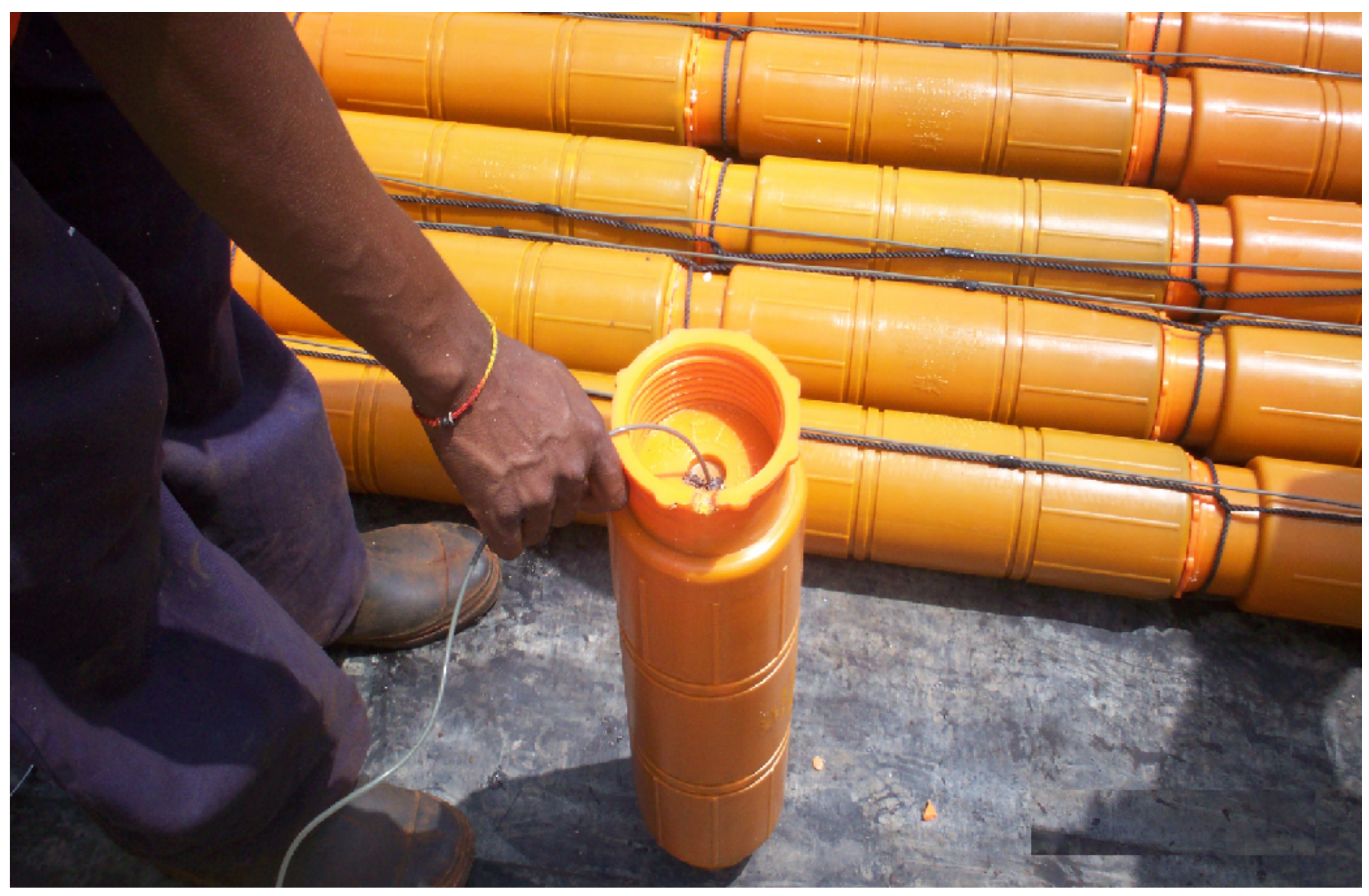

Figure 3

Couplable Plastic Tube Watergel Explosives 


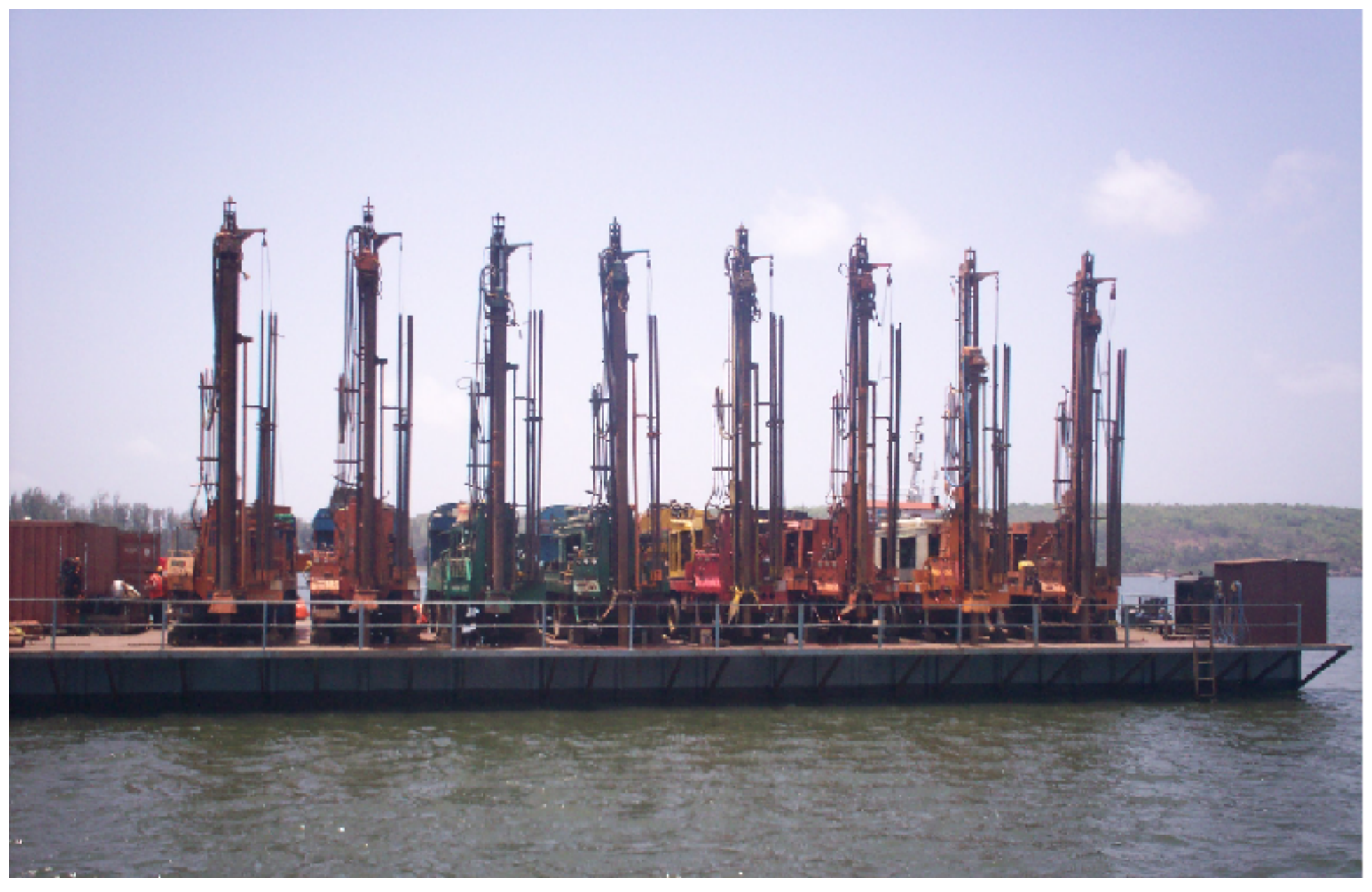

Figure 4

Drill and Blast Barge 


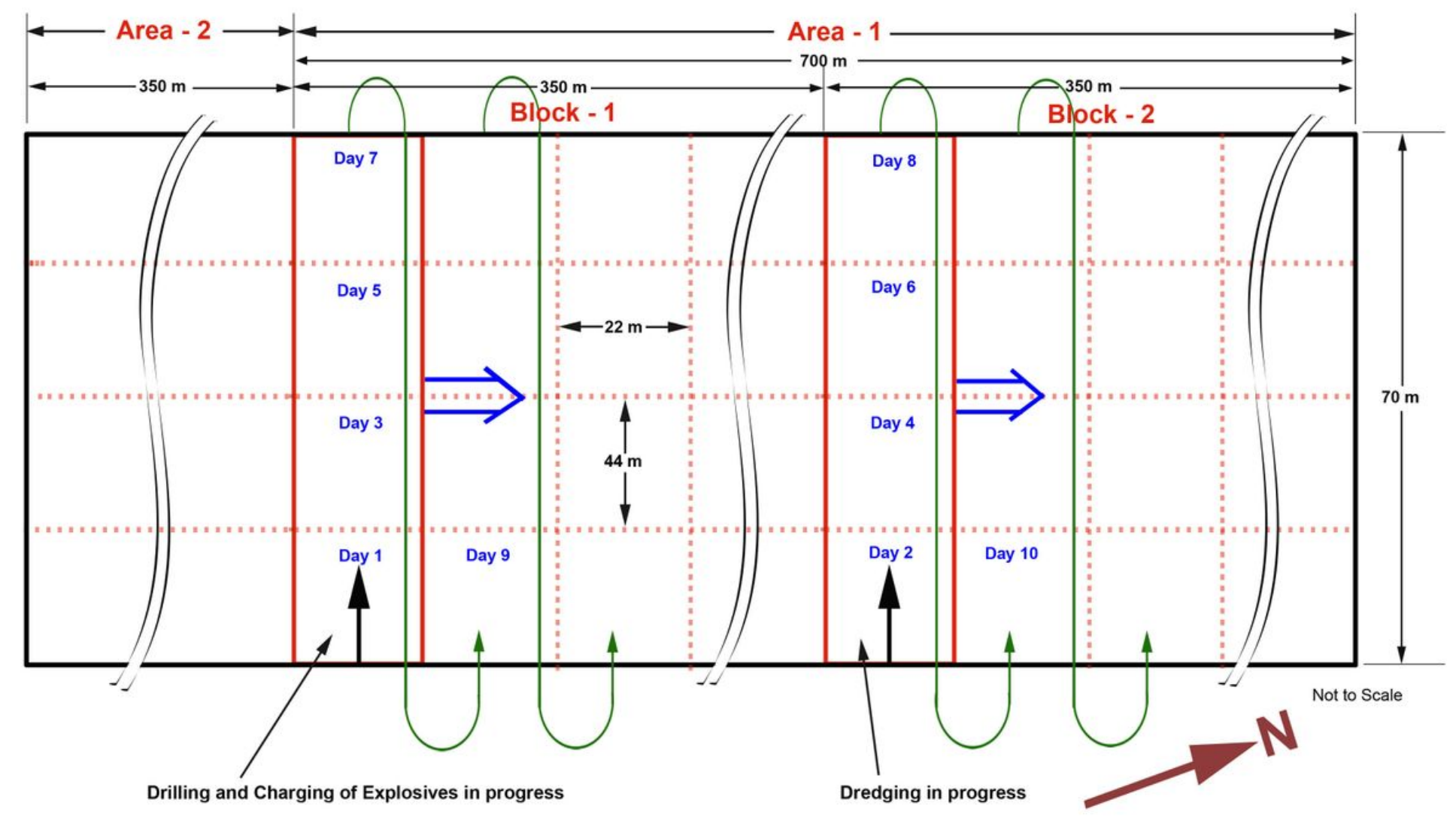

Figure 5

Preparation of two faces for the Drilling and Blasting and Dredging Operations alternatively 


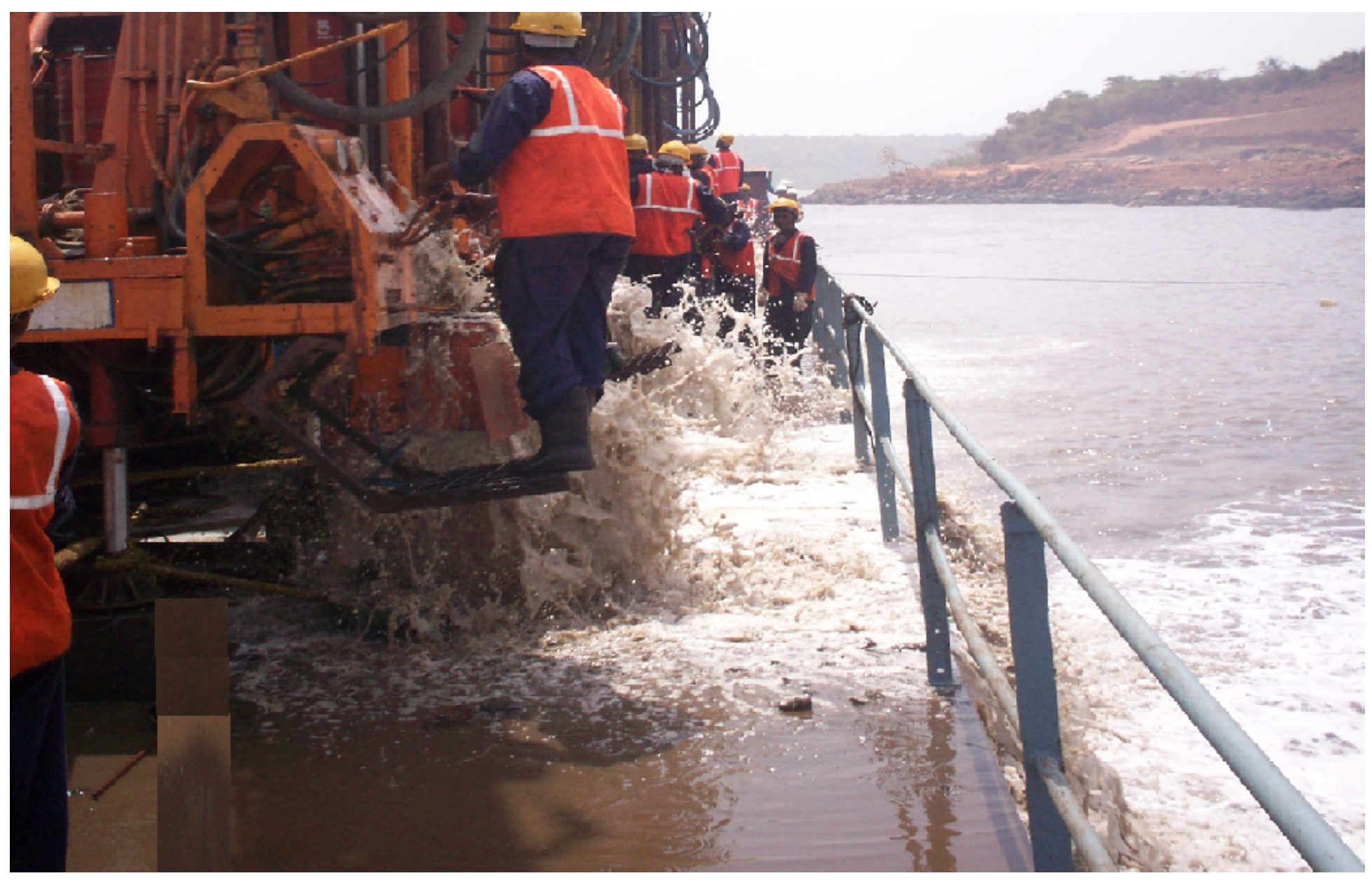

Figure 6

Drilling Operations in the Barge 


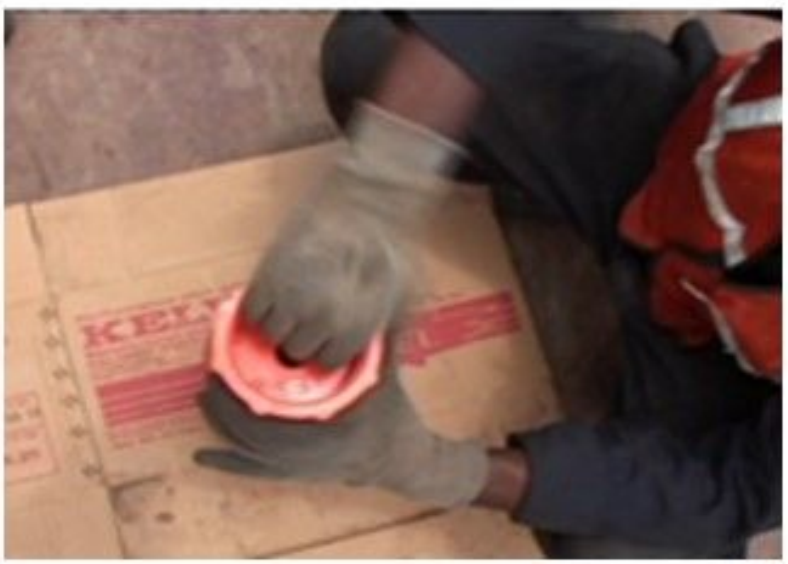

(a) Opening of threaded cap of CPT Cartridge

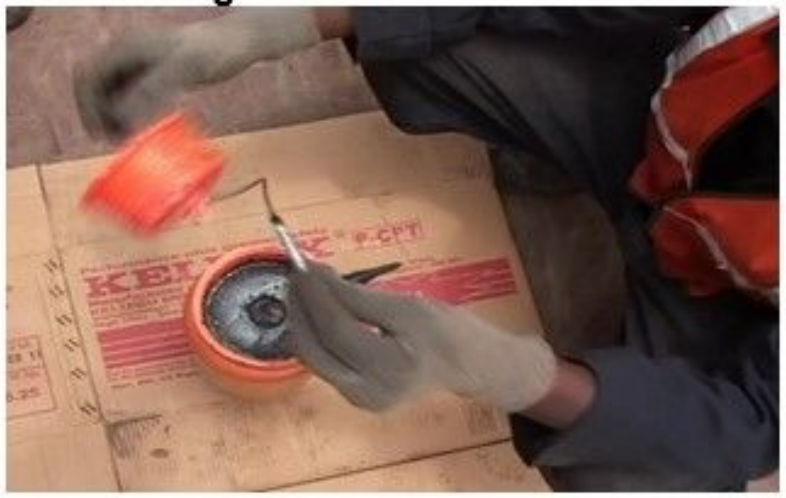

(c) Inserting shock tube through threaded cap of CPT Cartridge

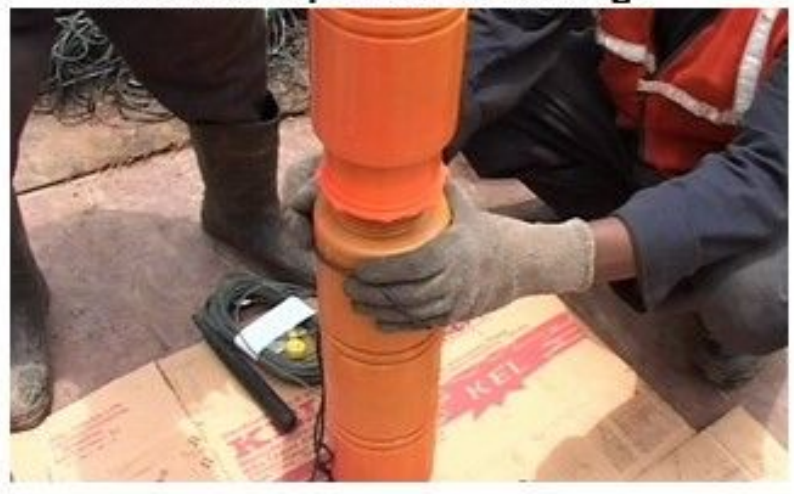

(e) Threading of additional CPT cartridges with primed Cartridge

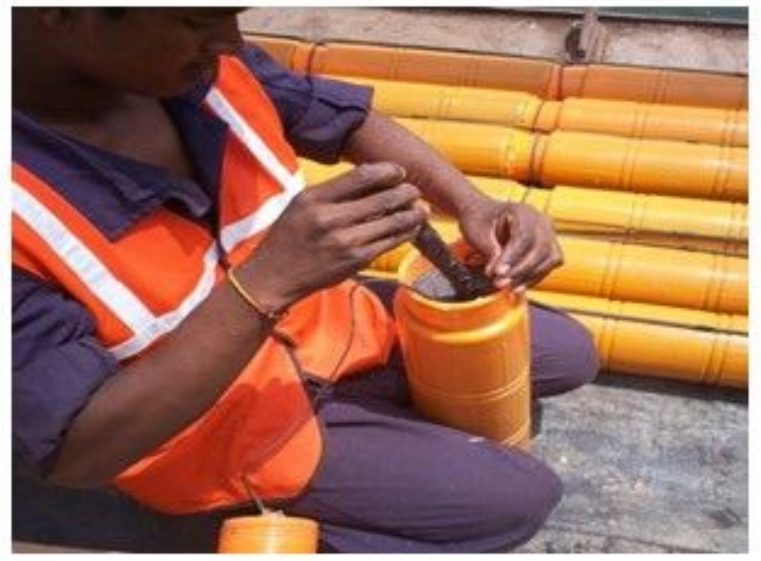

(b) Pricking of CPT Cartridge

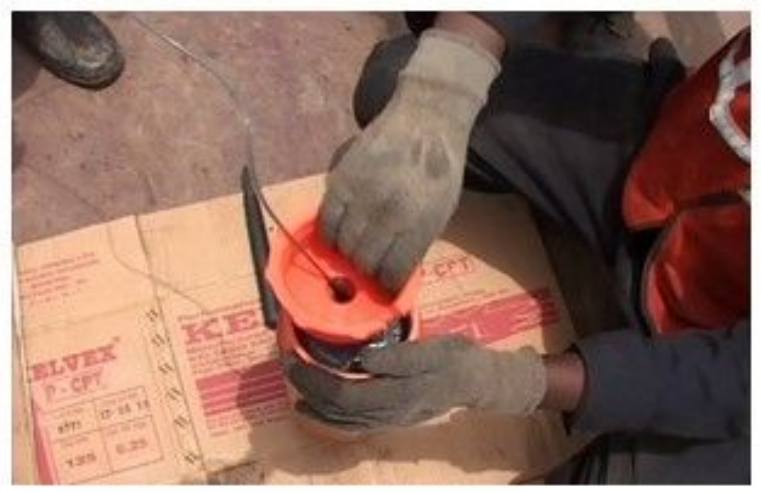

(d) Fixing the cap back to CPT Cartridge

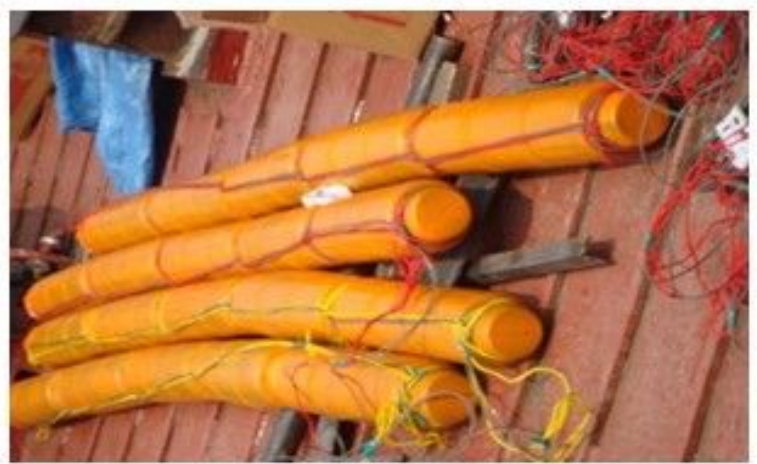

(f) Primed CPT Cartridges ready for charging

Figure 7

Various Stages of Priming of CPT Cartridges with NONEL shock tube initiation system 


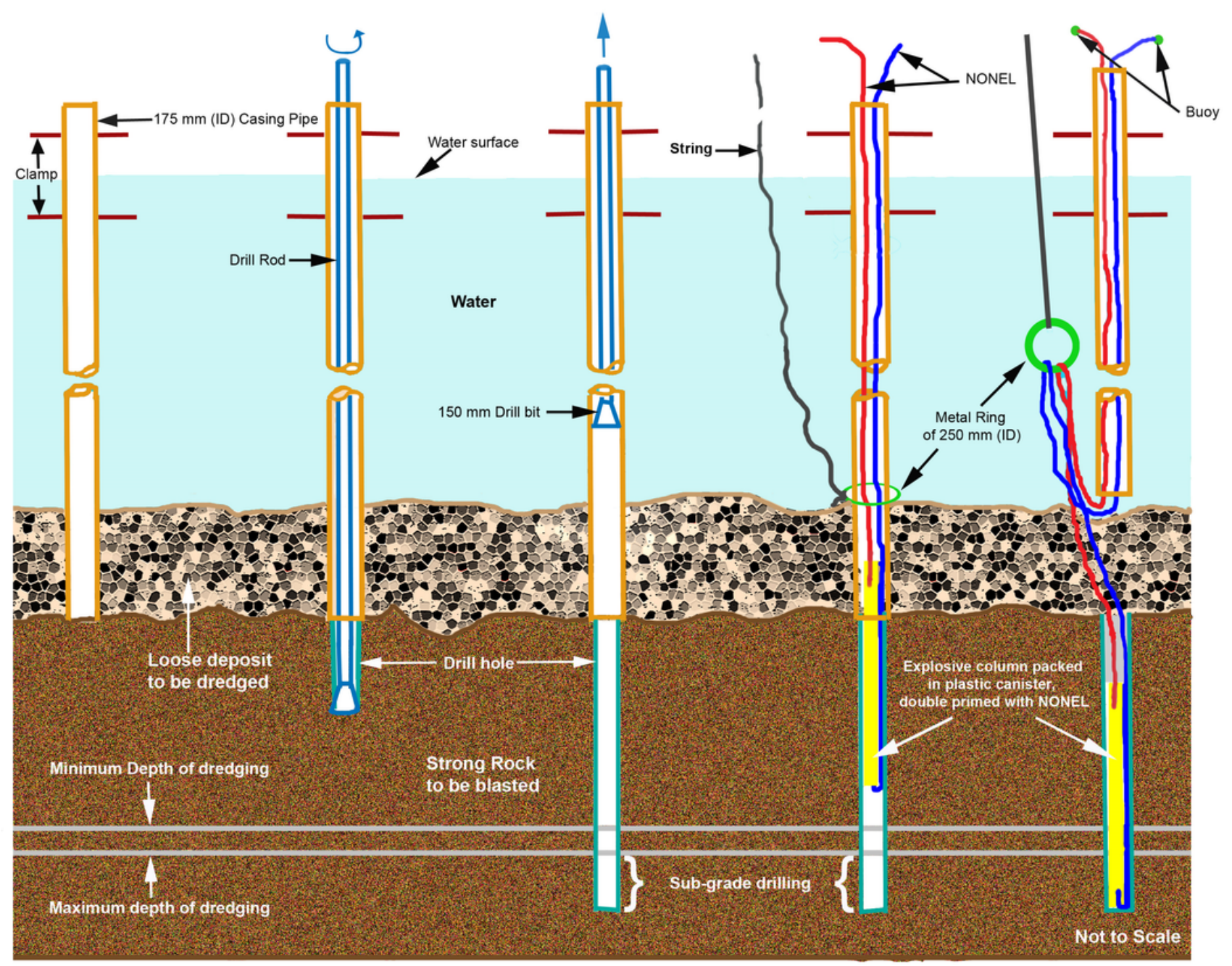

a) Lowering of Casing Pipe

b) Drilling through Casing Pipe

c) Drill Steel being

d) Charging the hole with explosives double primed with NONEL

e) Casing Pipe being withdrawn after charging the hole and recovering the second end of the NONEL

\section{Figure 8}

Drilling and Charging of the blastholes 


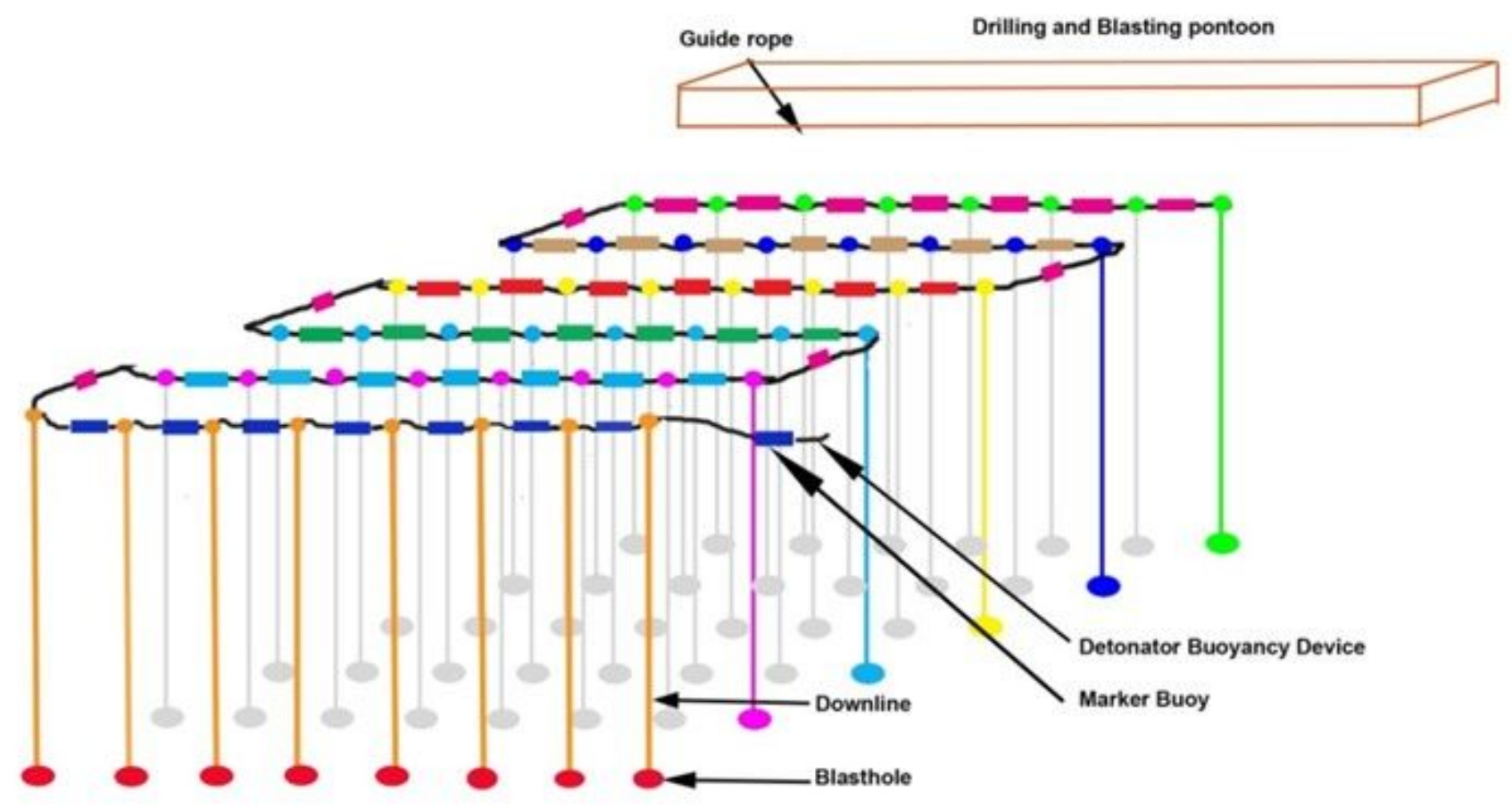

Delay Timing

$25 \mathrm{~ms}$ (between rows)

$17 \mathrm{~ms}$ (between hole)

Figure 9

Blast Initiation Hook-up diagram

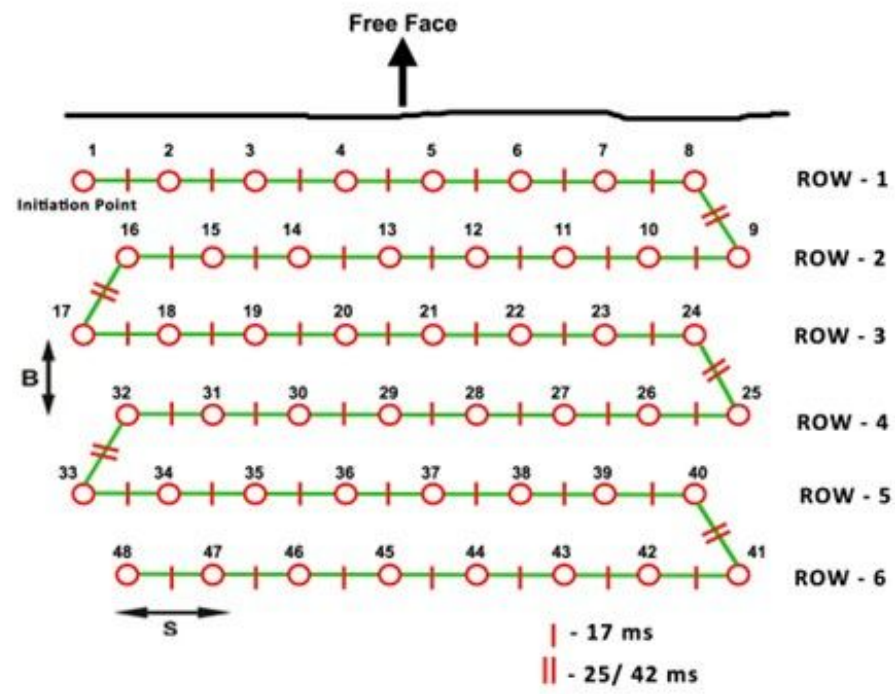

(a) Staggered drilling pattern and row-byrow initiation sequence

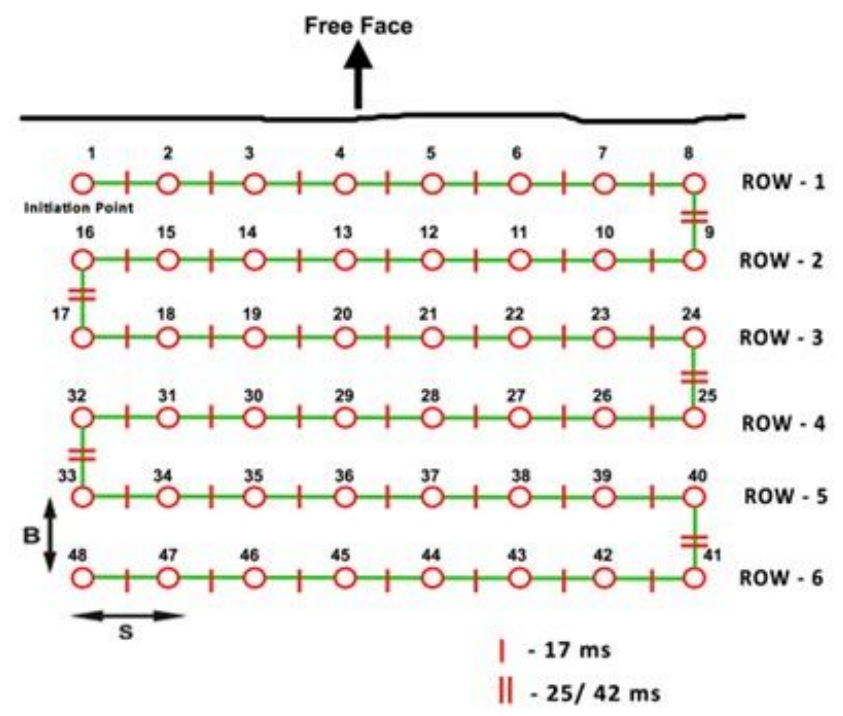

(b) Rectangular drilling pattern and row-by-row initiation sequence.

\section{Figure 10}

Drilling and Initiation Pattern for Blasting Operation 


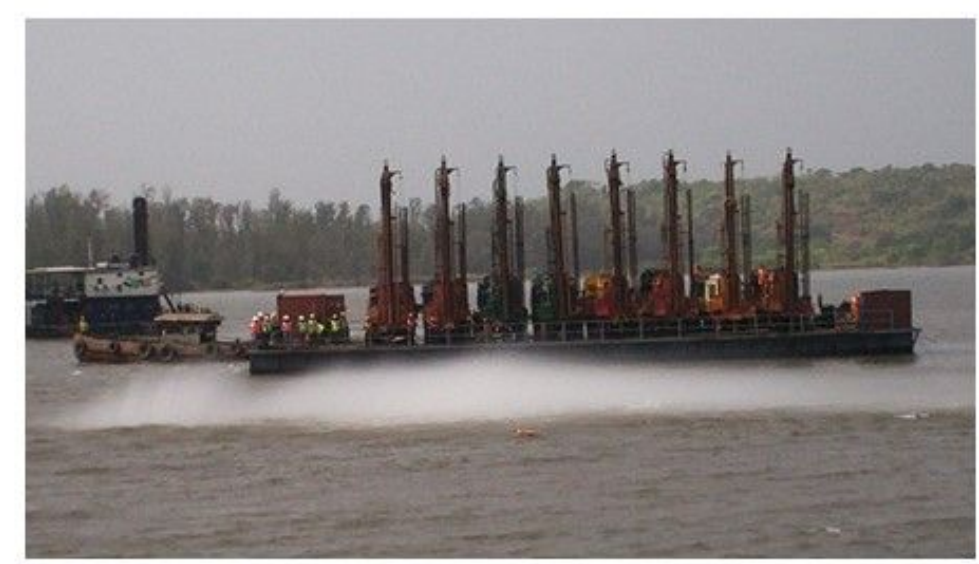

Shockwave Spray

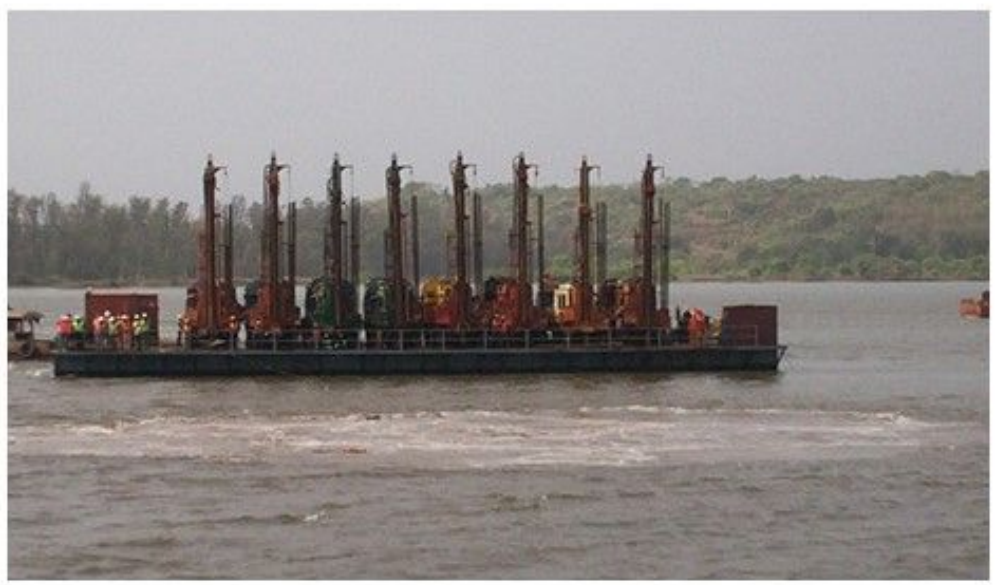

Rock and Mud Ejection

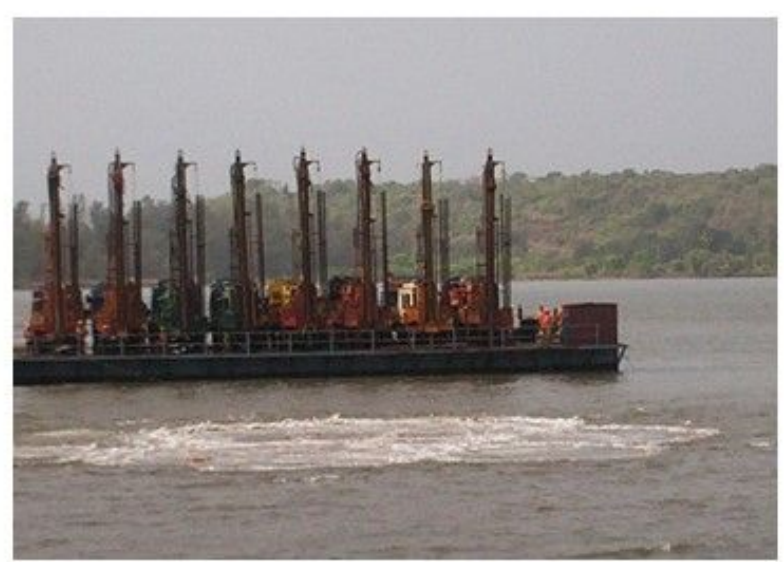

Surface Expression

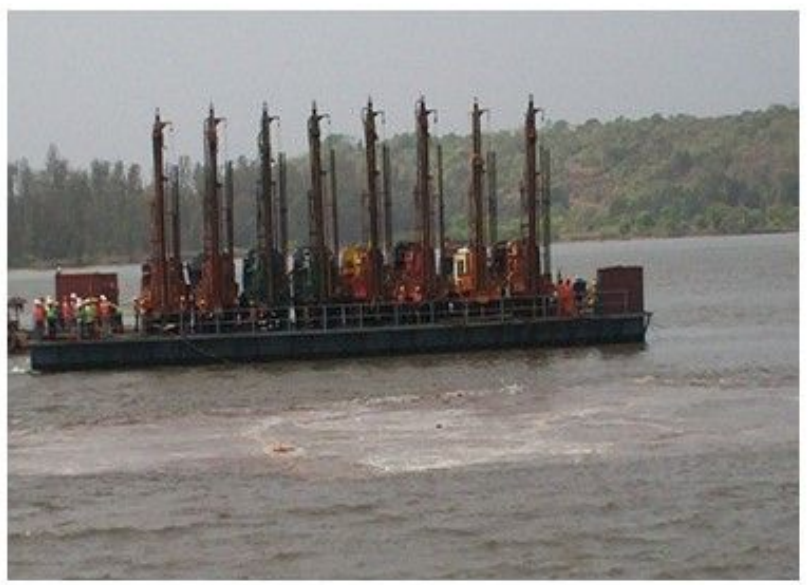

Gentle Rising

Figure 11

Stages of an Underwater Blast 


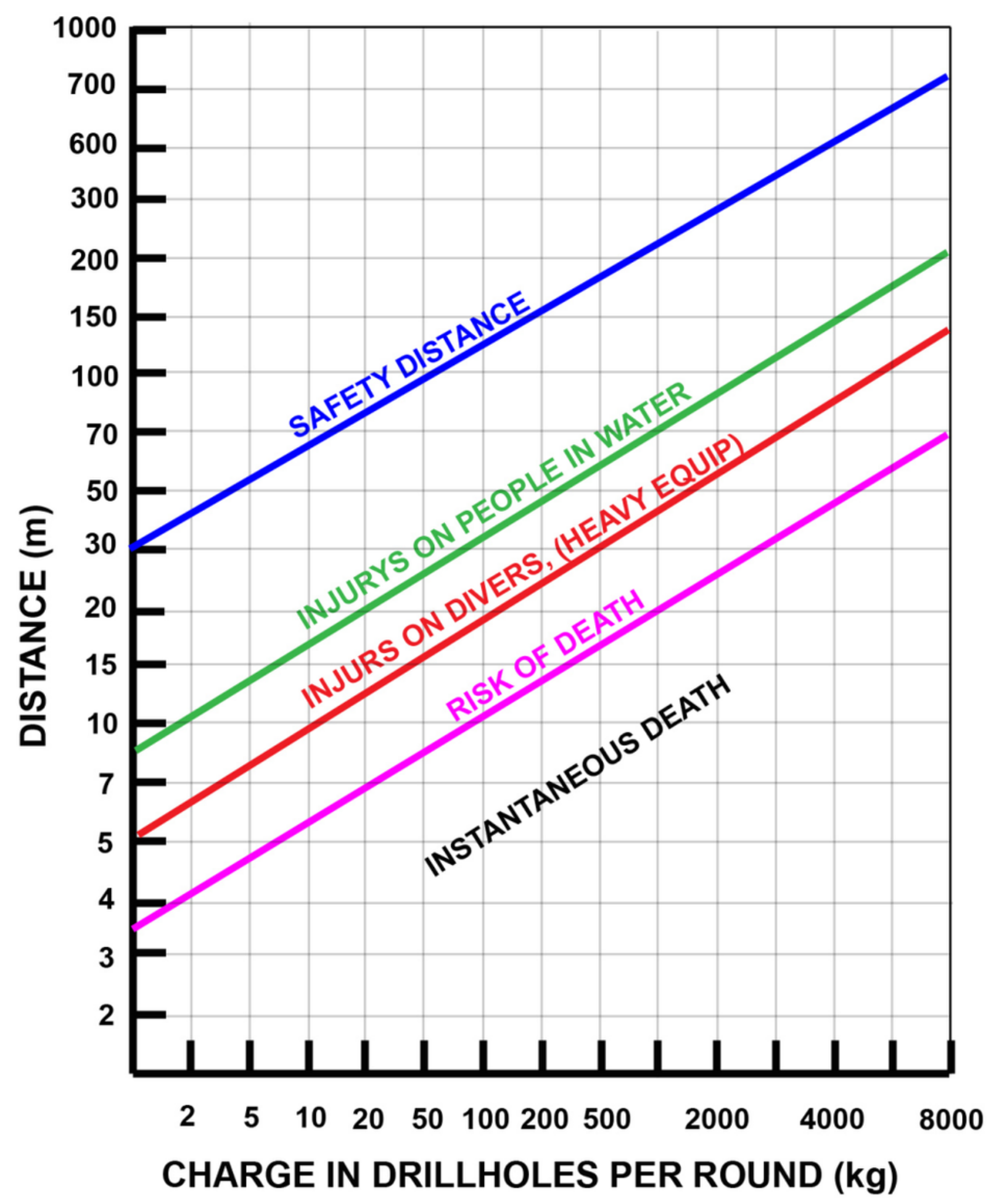

Figure 12

Safety distances for different explosive charges (Jimeno et al, 1995) 